\title{
La génesis del «cerco» internacional al régimen del general Franco (1945-1947)
}

\author{
Luis Antonio Buñuel Salcedo
}

\section{ESPAÑA ANTE EL FIN DE LA GUERRA MUNDIAL}

Desde que en el mes de octubre de 1943 España retomó su neutralidad de una no-beligerancia sospechosa, estuvo claro que en la política exterior del Régimen se había operado un cambio.

La marcha de la guerra en Europa, al ser puesto en jaque gravemente el poderío de la Wehrmacht obligó - aunque a regañadientes-a ir tomando una serie de medidas que fueran del agrado de las potencias demoliberales: la expulsión de agentes alemanes del norte de Africa; el cierre de sus oficinas diplomáticas en Tánger; el cese de las filtraciones de información sobre movimiento de barcos aliados en el Estrecho de Gibraltar; y el famoso asunto del Wolframio ${ }^{1}$ que dio pie a unas largas negociaciones de carácter más general y que enajenarían definitivamente (salvo en el terreno propagadístico) a la España de Franco del Eje nazi-fascista para el resto de la guerra.

\section{ABREVIATURAS:}

PRO: Public Record Office. Archivo del Ministerio de Asuntos Exteriores Británico en Londres.

AMAE: Archivo del Ministerio español de Asuntos Exteriores en Madrid.

APG: Archivo de Presidencia del Gobierno, Madrid.

1 Véase el artículo "La consolidación del franquismo" de Antonio MARQUINA BARRio en el Tomo 20 de la Historia Universal del siglo XX de la revista Historia 16, pág. 124. 
La nueva neutralidad, pues, pudo ser calificada de «complaciente» por los aliados, debido en altísima medida a la dependencia económica, y a lo vital y trascendente que los suministros anglo-norteamericanos resultaban para el deshecho país.

Aunque es sabido que Franco no perdió la esperanza de que la guerra concluyera en un arreglo por agotamiento (la fortaleza europea era inexpugnable), su "zarraconería" de gallego, o la habilidad de su ministro de Asuntos Exteriores, hizo que la comprometida tendencia se torciera y que - según había instado el embajador en Londres- se abandonara ostensiblemente la germanofilia galopante en favor de la dura realidad.

El 27 de enero de 1945, José Félix de Lequerica y Erquiza a la sazón ministro de Asunto Exteriores, recibió un telegrama cifrado desde Londres $^{2}$ donde se le comentaba que no era previsible fuese tratada España en una inminente reunión de los Tres Grandes, pues aunque se quería ver al país como un modelo de neutralidad, entendía el remitente que los neutrales considerados podrían ser aquellos que «disfrutaban» de una comunicación directa con Alemania. Es decir, aquellos que podían contribuir al bloqueo definitivo del Reich: Estaba claro que España no estaba en condiciones de hacerlo.

Es evidente que las relaciones europeas del Régimen quedaban a estas alturas de la guerra bastante constreñidas: el Eje era, de todas todas, descartable al igual que la Rusia Soviética, tradicional antagonista; y el bloque demoliberal, deshecha y compartimentada Francia, se reducía a Gran Bretaña.

Ante esta nación se había intentado realizar un amplio revoco de fachada del Franquismo por medio de varias iniciativas políticas y de Prensa ${ }^{3}$, pero los resultados dejaban bastante que desear. Todo ello era muy lógico; a parte de los EEUU, el Reino Unido era la única entidad con poder decisorio importante en el núcleo aliado occidental, y a jugar su carta se afanaron los políticos españoles. Afirmar la vocación europea en perjuicio de otros valores e incluir el compromiso anticomunista, que no anti ruso, del Régimen fue el objetivo prioritario de la diplomacia franquista; pretendiendo contrapesar las medidas inglesas y estadounidenses que venían golpeando casi inmisericordemente al país.

2 Telegrama cifrado $n .{ }^{\circ} 65$, enviado por el encargado de negocios español en Londres al ministro de Asuntos Exteriores, 27 de enero de 1945. APG Legajo ${ }^{\circ}{ }^{\circ}$ 5. Jefatura del Estado.

${ }^{3}$ Sobre el particular puede consultarse el capítulo quinto de la Segunda parte de la Memoria de Licenciatura de Luis Buñuel Salcedo: "La Embajada de Jacobo Stuart, duque de Alba, en Londres. Una Misión de paz en tiempo de guerra (1937-1945)". UNED. 
Franco habia escrito a Winston Churchill en noviembre de 1944 una carta, en la que consideraba a España y a Gran Bretaña como las dos únicas naciones "viriles" de Europa, que habrian de empeñarse en una suerte de apostolado fraterno para impedir la invasión del Continente por parte de la URSS y cuya amistad, más que necesaria, resultaba imprescindible.

La reacción del Ejecutivo británico fue, como se puede suponer, absolutamente negativa, y aunque la respuesta se demoró, no careció de decepcionantes términos para la animosidad franquista.

Un periódico como The Observer decía al respecto por aquellos días:

\begin{abstract}
«Hase revelado ahora que Primer Ministro en días recientes ha contestado carta que Franco dirigióle en noviembre. General Franco aparentemente no comprendió bien proyectada unión Occidente misma manera que no comprendió palabras amables acerca de España. Es muy verosímil que interpretólo como pacto anti-komintern de democracias y apresuróse a ofrecer sus indeseables servicios" ${ }^{4}$.
\end{abstract}

Otro diario británico, el Daily Telegraph, comentaba en los primeros días de 1945 el contenido de la carta del "Generalísimo» recalcando la referencia a una

«...posible formación de una unión de países del Occidente de Europa en la cual España podría ser incluída para fines de defensa mutua, Sugirióse también que Gran Bretaña, Francia y España y, eventualmente Italia podrían elaborar una política mediterránea común” 5 .

La obsesión de Franco por obtener para España un sillón en la mesa de la paz es muestra del carácter de sus pretensiones y no desdice en nada el atormentado rumbo de su política exterior al fin de la contienda.

Como es lógico, buena parte de dicha política, aunque fuese referida al orden interior, pasaba también por las principales capitales europeas, en carne de exiliados. Estos, cuyos movimientos no vamos a tratar al

${ }_{4}^{4}$ Telegrama en clave del agregado de prensa español en Londres al ministro de Asuntos Exteriores, 29 de enero de 1945. APG. Legajo n. ${ }^{\circ}$ 5. Jefatura de Estado.

5 Ibid., pág. 2. 
detalle en estas páginas, como es lógico, constituyeron fuente de preocupación para el nuevo Estado.

Las agencias de noticias anglosajonas, por ejemplo, informaban de las actividades de eminentes exiliados en favor de un cambio de régimen en España al concluir las hostilidades. Forzando a la diplomacia española a realizar frecuentes gestiones de "seguimiento" ante los órganos internacionales competentes.

Un diplomático del Foreign Office nos ilustra:

«When the Spanish Charge D'Affaires come to see me yesterday I told him that we had noticed that there had been quite a lot of articles in the english papers recently about the supposed visits to this country of a number of prominent Spanish political refugees, such as Senor Olivan, Senor Prieto, and Dr. Negrin. The papers had suggested that all there individuals were collecting in England to get together and stent some conspiracy against the Spanish Government...

...I told him that as far as Olivan was concerned he had come here in connexion with the affairs of the permanent Court of International Justice... As regard Prieto, I told Santa Cruz that he had been coming to the World Trades Union Conference... As regards Negrin I explained that he was now in Paris and that if he did come back this would probably be only for a short time on his way to Mexico" ${ }^{6}$.

A propósito de la Conferencia de Crimea, el representante británico en Madrid - James Bowker- escribía el 20 de febrero un despacho a Anthony Eden (secretario del Foreign Office) comentando las reflexiones que hacia la prensa española sobre el particular.

Y luego de un breve análisis de los distintos puntos de vista, se hacía eco de los "hechos" que habrían de basar las buenas relaciones entre España y el Reino Unido, que era como decir con Europa:

1. La catastrófica situación de Europa tras la guerra había de impulsar a los pueblos del Continente a una leal cooperación. Inglaterra necesitaría a España como España necesitaría a Inglaterra.

2. España es una .zona de paz fundamental en el Mediterráneo. El Mediterráneo constituye un interés vital para Gran Bretaña. Una política mediterránea no es posible sin España.

${ }^{6}$ Nota interna del Foreign Office de fecha 13 de febrero de 1945. PRO FO 371/49.554. 
3. ${ }^{a} \quad$ España es una potencia del Mediterráneo occidental que tiene importantes intereses en el norte de Africa. Para salvaguardarlos es necesaria una política conjunta de España, Francia e Inglaterra.

4. ${ }^{a} \quad$ El orden mediterráno en la postguerra es una necesidad para Gran Bretaña.

5. El Imperio británico necesita amigos y colaboradores, grandes o pequeños en su gigantesco esfuerzo político y comercial tras la guerra.

6. ${ }^{a} \quad$ Entre Inglaterra y España existe una fuerte tradición comercial que es interés de los dos países reforzar e intensificar.

7. Ante la presencia de fuerzas antieuropeas en la sociedad cristiana, Inglaterra tiene una misión cultural cuando venga la paz. En esta tarea encontrará siempre a España dispuesta para cooperar ${ }^{7}$.

¿En base a qué, consideraba el representante británico, realizaba España semejante ofrecimiento para tales necesidades?:

PRIMERO: porque habíase dirigido colateralmente hacia Hispanoamérica, obviando cualquier otra excesiva influencia europea.

SEGUNDO: porque el Régimen jamás había creído en el «Nuevo Orden Europeo" y se había afanado por constituir un bloque ibérico independiente.

TERCERO: porque gracias a la no-intervención española en el norte de Africa se habia desarrollado sin contratiempos la operación aliada.

CUARTO: porque España se había comportado caballerosamente ante la derrota de Francia.

QUINTO: porque España había hecho todo lo posible por humanizar la guerra.

7 Despacho n. ${ }^{\circ} 114$ del embajador británico en Madrid al secretario del Foreign Office, 20 de febrero de 1945. PRO. FO 371/49.574. 
SEXTO: porque España no había tenido que ver con los poderes políticos embarcados en la guerra, ya que el Imperialismo estaba en contra de sus intereses.

SEPTIMO: porque la presencia de voluntarios españoles en el frente del Este no afectaba a la posición neutral del Régimen; reforzando la idea de que el pueblo español se oponía a la exportación del comunismo.

OCTAVO: porque España no había entrado en la guerra, ni tan siquiera en tiempos de clara pleamar del Reich.

NOVENO: porque España había rechazado las doctrinas políticas extranjeras, siendo los ideales de José Antonio y el «Caudillo» algo original y originario de España.

DECIMO: porque no se habian puesto dificultades a la propaganda extranjera en España.

UNDECIMO: porque la economía española había sido enfocada directamente a la reconstrucción nacional.

DUODECIMO: porque la presión del Eje había revalorizado la neutralidad española en los primeros compases de la guerra ${ }^{8}$.

Todos estos créditos habrían de avalar la justicia de la petición del régimen franquista de un lugar al sol en el entramado de la postguerra $y$, posiblemente, más aún, un sitio de preferencia en la reconstrucción de la paz europea. Sin embargo, 1945 era un año de grandes cambios: no supuso la apertura del dossier español pero sí el agudizamiento de su «enfermedad internacional».

Los exiliados lo veían así. En Argel, el cónsul general británico informaba el 26 de febrero de las actividades antifranquistas de los exiliados españoles que propugnaban -evidentemente - el retorno de la República ${ }^{9}$. Y en Madrid, Mr. Bowker (de la Embajada británica) se hacía eco de las actividades de monárquicos y militares (Kindelán, Aranda) en favor de un

${ }^{8}$ Despacho n. ${ }^{114}$ del embajador británico en Madrid al secretario del Foreign Office, 20 de febrero de 1945. PRO. FO 371/49.574.

9 Despacho del cónsul general británico en Argel a su ministro de Negocios Extranjeros, 26 de febrero de 1945. PRO. FO 371/49.554. 
convenio entre Franco y el pretendiente Don Juan de Borbón para la restauración pacífica del régimen monárquico. Al tiempo que destacaba el efecto que en la oposición interna al Régimen había tenido el Manifiesto de Lausana, censurado fielmente por los organismos competentes ${ }^{10}$.

Mayor alcance habían tenido las conversaciones entre el duque de Alba, embajador en Londres, y el general Franco sobre todo en lo relativo a las relaciones anglo-españolas; germano-españolas, y al futuro próximo de España. El brigadier Torr, agregado militar de la Embajada británica en Madrid refirió a su encargado de negocios una conversación mantenida con el duque de Alba el 5 de abril, de la que pudo deducir elementos esclarecedores del pensamiento político de Franco: En primer lugar, que el "Generalísimo" no estaba dispuesto a restaurar la Monarquía, ni en breve, ni a toda costa. En segundo, que estaba convencido de que Alemania no sería derrotada finalmente debido a que - pensaba Franco - en última instancia, cuando los ejércitos americano y ruso se encontraran, habrían de combatirse...

«...and then would come the chance of a resurgence of Germany, as the rulers of Germany well Kriew» (!).

$Y$, finalmente, que...

\begin{abstract}
«Franco must be well aware from his correspondence with Mr. Churchill that the maintenance of the Falange regime was already making cordial relations between England and Spain impossible. Franco replied that England was not of importance and that he did not even consider it worth while continuing the correspondence with Mr. Churchill as the latter's utterances were those of a lian who was a slave of freemasonry and who was the head of a corrupt and decadent country which, like himself, was under the control of international freemasonry. Spain's external relations therefore would in future be based on America and she could afford entirely to ignore Engiand $" 11$.
\end{abstract}

Como es fácil de suponer, el duque de Alba no podía seguir representando al régimen de Franco, precisamente, en Gran Bretaña si tales ideas eran las que movían la cabeza rectora de su país: su embajada sólo duró hasta octubre.

10 Telegrama cifrado del embajador británico en Madrid al Foreign Office, 24 de marzo de 1945. PRO. FO 371/49.629.

11 Comunicado interno secreto n. ${ }^{\circ} 151 / 45$ del agregado militar al encargado de Negocios Británico en Madrid, 6 de abril de 1945. PRO. FO 371/49.629. 
En Francia, desde varias ciudades del territorio colonial y metropolitano fueron enviadas notas de protesta a la Embajada británica en París pidiendo la ruptura de relaciones diplomáticas con la España franquista. El representante británico en la capital francesa escribía el 21 de abril al Foreign Office haciéndose eco de actividades en igual sentido por parte de la Unión Nacional Española, grupo preferentemente comunista que resultaba especialmente activo en el sureste del país vecino ${ }^{12}$.

Las cosas no podian ser más sencillas, ni más clara la postura aliada frente a España. El embajador de Londres - generalmente muy bien informado - escribía a Lequerica el 24 de abril, nada menos que lo siguiente:

"1. Que debido a recientes acontecimientos y tal vez por haber recibido este Gobierno informaciones de Madrid más fidedignas y menos apasionadas, los elementos responsables de Londres están más al corriente hoy día de lo que estaban hace meses sobre cuál es la verdadera situación en España y saben, por lo tanto, que no se producirán en un próximo inmediato los cambios que aquí se desean y se daban como descontados no ha mucho.

2. Que el hecho de que se comprenda ahora algo mejor la realidad española, lejos de producir una reacción favorable, ha exacerbado la animosidad y la hostilidad hacia el régimen actual de España. Antes se creia que con sólo esperar se produjera el cambio, y hoy se sabe que los españoles aborrecen la idea de cualquier división interna que pueda llevarlos a una segunda guerra civil.

3. Que como consecuencia de la estabilidad política española, por un lado, $y$, por otro, el firme propósito de los aliados vencedores de dificultar en cuanto puedan la existencia de lo que ellos consideran el último régimen totalitario del tipo (no comunista) que ellos se han propuesto exterminar, se mantendrá a España durante una temporada aislada o alejada de la comunidad internacional, tratándose de molestarnos lo más posible. Esa temporada de aislamiento será más o menos larga, según tarden en producirse diferencias entre las Naciones Unidas, o según se produzcan cambios en las orientaciones políticas de sus gobiernos, pues todas esas elecciones generales tan anunciadas en la mayoría de los países de Europa, pueden llevar al poder gente de color político distinto al de los actuales gobiernos» ${ }^{13}$.

El Régimen, pues, estaba al cabo de la calle de los más inmediatos designios aliados. De hecho, a España se le excluye de la Conferencia de San Francisco, a pesar de que el diplomático Angel Sanz Briz, destacado en dicha ciudad norteamericana, informaba el 7 de mayo de la escasa referencia que en aquel foro se había hecho del Régimen y a la casi nula

12 Despacho n. ${ }^{\circ}$ 126/26/45 de Mr. Becclett, de la Embajada británica en París, al Foreign Office, 21 de abril de 1945. PRO. FO 371/49.555.

${ }^{13}$ Despacho del marqués de Santa Cruz, de la Embajada de España en Londres, al Ministerio de Asuntos Exteriores, 24 de abril de 1945. APG. Legajo n. ${ }^{\circ}$ 5. Jefatura de Estado. 
influencia de los «rojos», quienes no habían sido admitidos como «parte» del proceso aglutinador que habría de desembocar en las Naciones Unidas $^{14}$.

Parece que la escasa acción exterior - no defensiva- del régimen franquista giraba en torno a un viejo proyecto neutralista, es decir, la idea nunca suficientemente culminada de formar un bloque neutral de países que pudiese servir de bisagra entre los otros dos sistemas que se empezaban a perfilar claramente. Los aliados también sabian de esto y sin darle más importancia de la que realmente tenía, siempre estuvieron en posición de cortocircuitarlo ${ }^{15}$.

O como nos dice Ramón Tamames:

\begin{abstract}
«De poco sirvió que en reajuste del Gabinete español el 18 de julio de 1945 se eliminase como ministerio la Secretaría general del Movimiento; y que se sustituyese a Lequerica por Martín Artajo, dando entrada en el Gobierno a los católicos de la ACNDP; y que se redujese en apariciencia la influencia de los falangistas al suprimir oficialmente por decreto de 11 de septiembre de 1945, el saludo brazo en alto. La condena internacional del régimen se puso en marcha en la primera reunión de la ONU en San Francisco, el 26 de junio de $1945{ }^{16}$.
\end{abstract}

Esta labor de mimetización del régimen de Franco no consiguió, sin embargo, los objetivos previstos. El dos de agosto y en la Conferencia de Potsdam, los "tres grandes" condenan al franquismo y, como apunta muy bien Rosario de la Torre:

"La realidad es que no fue Stalin el único responsable del ostracismo del régimen español. En primer lugar, también la Francia de De Gaulle hizo causa común con la URSS a la hora de pedir una acción fuerte contra el Gobierno de Madrid. En segundo lugar, no podemos olvidar que Truman fue un importante antifranquista que debía tener en cuenta no sólo las presiones de sus aliados en Europa, en particular gauliistas y laboristas, sino los deseos de la opinión pública norteamericana, igualmente antifranquista" 17

14 informe del diplomático español, Angel Sanz Briz, destacado en San Francisco, al Ministerio de Asuntos Exteriores, 7 de mayo de 1945. APG. Legajo n. ${ }^{\circ} 6$. Jefatura de Estado.

${ }_{15}$ Sirvan de ejemplo el despacho secreto WF 316/40 del Dominions Office a Mr. Hoyer Miller, del Foreign Office, 4 de mayo de 1945 y la contestación a aquél (documento Z 5.714/ 5.714/41, de 24 de mayo del mismo año. PRO. FO 371/49.649.

16 Ramón Tamames. La República. La era de Franco, Historia de España “Alfaguara” VII. Ed. Alianza, Madrid-1981. p. 56.

17 Rosario de la ToRre. "De la paz virtual a la guerra fría" en Historia Universal del siglo $X X$, volumen 19 Historia 16, pág. 16. 
En Madrid, el subsecretario de Exteriores, Cristóbal del Castillo, refiere a Martín Artajo una conversación mantenida con Mr. Bowker, donde el diplomático británico le expone sus opiniones respecto al acuerdo de Postdam, instando al régimen español a efectuar cambios en el Gobierno, a crear una "norma jurídica" para los españoles y a celebrar unas elecciones de acuerdo a la Ley de bases de administración local. Bowker cree que de no tenerse en cuenta estas recomendaciones antes del mes de septiembre...

"el acuerdo de Potsdam tendría consecuencias más serias para nosotros" 18.

\section{LAS DIRECTRICES DE ARTAJO}

Conviene tener muy presente la fundamental aparición en la escena político-diplomática española de Alberto Martín Artajo, sobre todo en lo concerniente a determinadas futuras facetas exteriores del Régimen.

En el colmo de la operación de blanqueamiento de fachada, el 11 de agosto de 1945, Martín Artajo cablegrafió al representante de España en Londres unas instrucciones de acción general (defensivas, por supuesto) que podrian hacer sonreír al más circunspecto político aliado, y que iban encaminadas a justificar un supuesto ideal de orden interno y organización en la práctica del neutral maldito en que se había convertido a España:

"1. No adelante, en lo posible, injerencia en asuntos internos de España. 2. Haga ver nuestro Régimen es de constitución abierta evolutiva en constante perfeccionamiento alejado de su base de partida por conveniencia pueblo y enteramente susceptiole acomodarse futura estructura España. 3. Acentúe postura simpatia para sentido social partido Laborista que no causa aprensión sino en reducida zona capitalista, pero encuentra comprensión en masa popular española que forma base del Régimen. 4. ${ }^{\circ}$ Subraye progresiva importancia labor Cortes y su futura evolución carácter representativo, así como nueva ley municipal, que da base democrática Ayuntamientos y Diputaciones. $50^{\circ}$ Exprese dolor pais injusta calificación declaración Potsdam, que supone ignorancia situación real española" 19.

18 Despacho del subsecretario de Asuntos Exteriores a Alberto Martín Artajo, Madrid, 7 de agosto de 1945. APG. Legajo n. ${ }^{\circ} 6$. Jefatura del Estado.

${ }_{19}$ Telegrama n. 12 cifrado del ministro de Asuntos Exteriores al embajador de España. en Londres, 11 de agosto de 1945. APG. Legajo n. ${ }^{\circ} 6$. Jefatura del Estado. 
Huelgan, por supuesto, los comentarios.

El diseño de la política exterior europeizante de España hecho por Martín Artajo, tomó, bien es cierto, tintes algo diferentes a los empleados hasta ese momento, enfocando la actividad diplomática positiva (esto es, no estrictamente defensiva) hacia los puntos más ideológicos de las personas a quienes estaba dirigida. El 14 de agosto de 1945 cablegrafió a los representantes de España en Lisboa, Londres, París, Roma y Santa Sede, instrucciones tendentes a recalcar determinados puntos fundamentales de la idiosincrasia del franquismo.

Instaba, por ejemplo, a utilizar a los residentes españoles en el extranjero - una vez "saturados" de la propia ideología - como catalizadores de una dialéctica pro-España que habría de ser equivalente a pro-franquista. Asimismo, se trataría de excitar la animosidad de los jerarcas de la Iglesia local contra los exiliados, tildados de masones y comunistas. $Y$, finalmente, de convencer a universitarios, intelectuales y hombres influyentes en los medios económicos de los peligros revolucionarios que corrían al tiempo en España y la verdad que ella encarnaba ${ }^{20}$.

Es notorio, en esta línea, el especial cuidado del ministro con el Vaticano, quien días después telegrafiaba a su embajador en Roma rogándole expresase al Papa la "perfecta identificación" de España con el discurso pronunciado por el Pontífice con motivo del final de la guerra ${ }^{21}$. Ejemplo preclaro de una maniobra de gran estilo que con el tiempo habría de configurarse como de vital importancia para la aceptación del Régimen en Europa y el Mundo.

Es más, desde su retiro estival en San Sebastián, el 21 de agosto de 1945, escribía Artajo al nuevo embajador británico, Sir Víctor Mallet, el resumen de la postura del franquismo una vez asumida en todos sus extremos la victoria laborista en las elecciones generales celebradas en el Reino Unido. En líneas generales abundaba en la idea de que el Régimen tenía un carácter evolutivo que le habría de alejar de sus posiciones de partida y que, respaldado mayoritariamente por el pueblo español, estaba "preparado para acomodarse a la futura estructura europea". Reiterando

20 Telegrama n. ${ }^{\circ 14 / 16}$ del ministro de Asuntos Exteriores a los jefes de misión en Lisboa, Londres, París, Santa Sede y Roma-Quirinal, 14 de agosto de 1945. APG. Legajo n. 6. Jefatura del Estado.

21 Telegrama cifrado n. ${ }^{\circ} 2$ del ministro de Asuntos Exteriores al embajador de España ante la Santa Sede, 16 de agosto de 1945 APG. Legajo n. ${ }^{\circ} 6$. Jefatura del Estado. 
la comprensión y aceptación que los españoles tenían por y hacian del Laborismo, cuya ideología les resultaba, cuando menos, "simpática" 22.

Sir ("Ivo") Victor Mallet se hacía eco en sus primeras impresiones de la repugnancia con que se veía en España, tanto la posibilidad de una nueva guerra civil, como a ciertos líderes republicanos en el exilio y aconsejaba a su ministro Ernest Bevin, cierta cautela y la concesión a España de un impasse de tiempo para estudiar más detenidamente lo que era oportuno hacer con el franquismo ${ }^{23}$.

Alberto Martín Artajo, consciente de la dificilísima situación externa de España y sabedor de las tiranteces que producían los hechos de la guerra en su propio "bando": conspiración de generales, malestar de monárquicos, etc. escribía al duque de Alba, embajador en Londres, una interesantísima aunque breve carta, el 22 de agosto, donde le instaba a defender la Patria - que no el Régimen, ni tan siquiera Franco- de los enemigos "rojos", recordándole los horrores que sus líderes habian traído a España en épocas pasadas y rogándole fueran pospuestas...

“... para el momento oportuno las distinciones internas en el campo nacional, sin olvidar que sólo dentro de él, como lo ha ofrecido el Generalísimo, hallarán un día satisfacción los legítimos anhelos de llegar a una situación definitiva conforme a la tradición monárquica del país" ${ }^{24}$.

Estaba claro: para hacer frente a los embates externos, el Régimen tenía que permanecer unido internamente, a despecho de rencillas y tendencias declaradas, procurando mostrar a los ojos aliados una suerte de look monolítico que destilara firmeza y cohesión por los cuatro costados.

En otro orden de cosas, el 7 de septiembre, un miembro de la Embajada británica comentaba un encuentro con $\mathrm{M}$. Roché diplomático de la Embajada francesa en Madrid, quien le había sondeado acerca de la posición adoptada por el Foreign Office respecto de la proclamación en Méjico de un gobierno republicano en el exilio, arguyendo que entendian como deseo de la gran masa del país el rechazo a la imposición de cualquier legalidad de fuera ${ }^{25}$.

22 Carta particular de Alberto Martin Artajo al embajador británico en Madrid, San Sebastián, 21 de agosto de 1945. APG Legajo n. ${ }^{\circ} 6$ Jefatura del Estado.

23 Telegrama secreto Z 9328/233/41 enviado por el embajador británico en Madrid a su ministro de Asuntos Exteriores, 10 de agosto de 1945. PRO FO 371/49556.

${ }^{24}$ Despacho del ministro de Asuntos Exteriores al embajador de España en Londres, 22 de agosto de 1945. APG Legajo n. 6 Jefatura del Estado.

${ }_{25}$ Nota interior del Foreign Office que reproduce la conversación entre Monsieur Roché. 
En todo caso, el Quai D'Orsay no había diseñado todavía una postura fuerte sobre el problema español y parecía seguir las directrices de Londres. Ahora bien, las elecciones cantonales francesas de la primavera de 1945 habían sido ganadas por la fuerzas social-comunistas que constituian el único poder legal democrático en la Francia del Gobierno Provisional de De Gaulle; por tanto influían poderosamente en el rechazo que el régimen de Franco cosechaba en la Europa liberada, y prepararon la iniciativa de fin de año en pro de una ruptura conjunta de las relaciones diplomáticas y económicas a cargo de los Estados Unidos, Gran Bretaña y Francia.

El 4 de enero de 1946, el semanario británico Spectator, enjuiciaba las relaciones hispano-francesas, y aunque reflejaba. las presiones del importante grupo comunista de la Asamblea Nacional en el sentido de forzar a su Gobierno a realizar actividades pro-República en España, (recuérdese el contencioso de la ejecución de Cristino Garcia y otros republicanos, un mes después), y consideraba grave la responsabilidad de De Gaulle en el caso de que auspiciase en su territorio las actividades de un Gobierno de exiliados, con el riesgo de que pudieran propiciar una nueva guerra civil en España ${ }^{26}$.

Cuatro dias después, Martin Artajo enviaba un telegrama al nuevo embajador español en Londres -Domingo de las Bárcenas y López Mollinedo- instruyendo su actitud frente a los claros ataques que se estaban vertiendo contra España. El tono general del comunicado acentuaba la necesidad de pedir tiempo para que el Régimen pudiera evolucionar favorablemente en el sentido más acorde con el progreso. Postulaba Artajo la necesidad de hacer comprender en Gran Bretaña lo necesario que era conseguir una España en paz en medio del "caos" europeo, para lo cual habría que abstenerse de toda inmiscusión en los asuntos internos del pais, con objeto de llevar a la práctica medidas de clemencia; aplicación correcta del Habeas Corpus; tramitación legal de un proyecto de ley sobre asociaciones y reuniones; la tolerancia de cultos; la reorganización de los servicios de prensa, y unas elecciones municipales que procuraran unas Cortes más representativas. Premisas éstas que deberian homologar al franquismo con el nuevo orden europeo según conviniese a los intereses políticos de Gran Bretaña, país-modelo del comportamiento de otras potencias:

de la Embajada francesa en Londres, y un funcionario británico. 7 de septiembre de 1945. PRO FO $371 / 49556$.

${ }^{26}$ Spectator, n. ${ }^{\circ} 6132$ de 4 de enero de 1946. 
“... debe V.E. insistir señalando que este programa ya en marcha y el espiritu patriótico con que Gobierno se preocupa de llevarlo a cabo exigen una etapa de desarrollo que no puede ser acortada con coacciones e intromisiones en asuntos de régimen interior que siempre merecieron respeto de Gobierno y pueblo inglés. Las impresiones que por diferentes conductos me llegan revelan claramente que tanto Estados Unidos como Francia no desean tomar iniciativa alguna con respecto a España y que se inspirarán en la actitud que Londres adopte. La importancia de cuanto ahi se haga es por tanto capital por lo que juzgo superfluo encarecer de V.E. que en esta ocasión es preciso emplear a fondo los medios de que V.E. disponga para evitar que pueda prosperar cualquier maniobra antiespañola" ${ }^{27}$.

A finales del mes de enero de 1946 fue conocida la composición del nuevo Gobierno francés, en el que participaban, con gran influencia, los comunistas. Consciente de que dicho ejecutivo se proponía romper relaciones con España, a despecho de la influencia de De Gaulle, Alberto Martín Artajo envió el día 27 una circular secreta a todos los jefes de misión en el extranjero, donde hacia una importante serie de consideraciones que nos resultan esclarecedoras para advertir el verdadero tono de la política española para con el país situado en el otro extremo del eje de influencias europeo.

Afirmaba Artajo que, en caso de ruptura de relaciones con Francia, habría que tener muy en cuenta:

1. ${ }^{\circ}$ El caos que podría determinar la caída de De Gaulle.

2. La intención comunista de hacerse con el Gobierno en Francia.

3. La obediencia de dicho partido a Moscú.

4. El apoyo comunista a Alemania, URSS y sus acciones antibélicas antes y después de la guerra.

5. Los ataques comunistas a los países anglosajones y los problemas ocasionados en Grecia, Yugoslavia, Turquía, Japón, etc. siendo la acción contra España parte de ese plan.

(Intentando, de esta manera, "homologar" el caso español con los anteriormente citados, de manera que fuese directamente incluido en los centros de atención aliados).

${ }^{27}$ Telegrama n. 12 cifrado de Martín Artajo al embajador de España en Londres, 8 de enero de 1946. APG Legajo n. ${ }^{\circ} 8$ Jefatura del Estado. 
6. La previsible corta vida del Gobierno francés.

7. El apartamiento de España de las vicisitudes de los países vecinos.

(Una especie de principio de no-injerencia en los asuntos internos de los demás).

8. La no existencia de cuestión alguna pendiente entre España y Francia.

9. La existencia de un acuerdo comercial hispano-francés.

10. La desproporción entre los grandes intereses económicos franceses en España y españoles en Francia.

$11 .^{\circ}$ La pérdida de terreno que en caso de ruptura sufrirían los intereses franceses en beneficio de los anglosajones.

12. El acercamiento a dichos países que tendría España si hubiera hostilidad francesa.

13. El favorable balance para España de sus relaciones el país vecino.

14. La conclusión de que España no deseaba la ruptura con Francia pero que tampoco la temía ${ }^{28}$.

Ese mismo día, despachaba Artajo un telegrama al embajador español en Londres reiterando que la posible ruptura con Francia sería debida exclusivamente a motivos de orden interno, a pesar de no haber ningún contencioso pendiente entre los dos países. Confirmando que en caso de consumarse dicha ruptura, habría un acercamiento a Gran Bretaña, e instando que:

“... obtuviese V.E. una declaración del Foreign Office, aunque fuese verbal y confidencial, de que cualquier actitud francesa no ha de encontrar eco en Gobierno británico" ${ }^{29}$.

28 Circulares cifradas $n .{ }^{\circ s} 16,17,18,19,20$ y 21 a todos los jefes de misión española en el extranjero. 27 de enero de 1946. APG Legajo n. 8 Jefatura del Estado.

${ }_{29}$ Telegrama cifrado $\mathbf{n} .^{\circ} 62$ del ministro español de Asuntos Exteriores al embajador en Londres, 27 de enero de 1946. APG Legajo n. 8 Jefatura del Estado. 
En resumen, la política exterior española tenía una clara directriz que estaba improntando toda la labor de maquillaje del Régimen. Se jugaba a la carta anticomunista, católica y anglosajona adivinando fácilmente que la única tolerancia de que podrían beneficiarse vendría dada por la fricción que tarde o temprano se habría de producir entre soviéticos y norteamericanos. Por eso mismo, en el punto quinto del más arriba mencionado telegrama había una clarísima inclusión del "problema español" en la lista de "problemas" globales que tenían las potencias occidentales.

La maniobra de homologación, aunque fuera en el estadio menos pacífico (España enemiga de la URSS), estaba muy clara.

Unos dias antes, el 25 de febrero, Víctor Mallet había analizado en pocas palabras las tres posibilidades que tenía la situación española de evolucionar, habiendo descartado la solución republicana: se permitía recomendar al Foreign Office jugar las cartas de la paciencia, apoyando las iniciativas subterráneas de negociación que debían existir entre el general Franco y Don Juan de Borbón, el pretendiente, vía algún destacado militar (como el general Aranda), para coadyuvar a una especie de salida intermedia que relegase a Franco al papel de moderador y permitiese una restauración monárquica controlada en la que fuese establecido una suerte de poder parlamentario en el que el Ejército resultase ser al garante del orden interior ${ }^{30}$.

No se desdeñaba la importante influencia de los intereses económicos ingleses en la Península, aunque sí el escaso prestigio que en el interior del pais parecian contar los líderes republicanos en el exilio.

El Gobierno español, celoso de su imagen exterior (imagen, por cierto, que llevaba años deteriorándose), remarcaba su voluntad de trabajar por la paz universal y la intención de gozar de plenas relaciones con los demás países. Y para ello volvía los ojos a Londres con auténtica insistencia, utilizando una y otra vez sus escasos argumentos neutralistas.

Ya era demasiado tarde para evitar la resolución de fecha 9 de febrero de las Naciones Unidas por la que no se había admitido a España como miembro de dicha Organización o impedir que en el mes de marzo Francia cerrara su frontera con España.

30 Despacho n. ${ }^{\circ} 69$ Z 1717/45/41 enviado por el embajador británico en Madrid a su ministro de Asuntos Exteriores, 25 de febrero de 1946. PRO FO 371/60375. 


\title{
EL CIERRE DE LA FRONTERA FRANCESA. EL COMIENZO DEL “CERCO”
}

Jean Descola, célebre historiador francés, en su no menos célebre libro titulado $O$ Espagne, preguntaba a Georges Bidault (ministro francés de Asuntos Exteriores en 1946) el porqué del cierre de la frontera el $1 .{ }^{\circ}$ de marzo del mismo año. Bidault afirmaba que ello se había debido a la presión hecha por el propio Gabinete, marcadamente izquierdista, que por entonces regía los destinos de Francia toda vez que De Gaulle se había retirado a "Colombey" luego de sufrir un voto desfavorable. (Sin embargo, las relaciones diplomáticas se mantenían a nivel de encargado de Negocios).

Al cierre de la frontera francesa sucedió, el 5 de marzo, una declaración conjunta de los Gobiernos francés, británico y norteamericano acordando:

\begin{abstract}
"... que mientras el general Franco siga gobernando España, el pueblo español no puede esperar una completa y cordial asociación con las naciones del mundo... No tenemos intención alguna de intervenir en los asuntos internos de España... Por el contrario, se confía en que personas españolas patriotas y de espiritu liberal encontrarán pronto la ocasión de conseguir una pacífica retirada de la Falange y el establecimiento de un Gobierno interino o provisional, bajo el cual el pueblo español pueda tener la oportunidad de determinar el tipo de gobierno que prefiere y escoger a sus jefes. Amnistía política, libertad de asociación política y la preparación de elecciones son esenciales. Un gobierno interino que decida a entregarse - y se mantenga en su esfuerzo- a estos fines, recibirá el reconocimiento y apoyo de todos los pueblos que amen la libertad. Ese reconocimiento incluirá relaciones diplomáticas totales y la adoptación de las medidas prácticas necesarias para solucionar los problemas económicos de España hasta donde se pueda, dadas las circunstancias de cada momento" ${ }^{31}$.
\end{abstract}

La iniciativa unilateral de cerrar la frontera no supuso, a la postre, para Francia más que importantes pérdidas económicas que potenciaron, por ejemplo, el mercado negro, sin obtener como contrapartida, ni la asfixia del régimen de Franco; ni el reconocimiento pleno del gobierno republicano en el exilio; ni, tan siquiera, la movilización de las fuerzas internas de oposición al franquismo, divididas y -en el caso de los generales- impregnadas de pesada inoperancia. (Salvo Aranda, desterrado en las islas Baleares.)

La postura portuguesa respecto al orden interno de España quedaba claramente del lado de Franco, entre otras cosas por afinidad de regíme-

31 Ramón Tamames, op. cit. pág. 517. 
nes. $Y$, prevaliéndose de su ancestral amistad, así se los explicaban al Reino Unidos las autoridades portuguesas.

El argumento luso esgrimido por el Dr. Matías al embajador inglés en Lisboa en marzo de 1946, giraba en torno, no a la intención aliada de provocar un rápido abandono del Poder por parte del general Franco, sino a la preparación del régimen político que habría de sucederle. Los portugueses se jactaban de conocer mejor que nadie el espíritu español, y consideraban inútil y perjudicial una actitud "a la francesa", sobre todo por el peligro de guerra civil a que pudiera conducir.

Prevenir un nuevo conflicto armado y recomendar la no intervención en los asuntos internos del país vecino eran los dos platos de la difícil balanza en que estaba ubicada la política española de los anglosajones:

\footnotetext{
"When I asked - decia el embajador de Gran Bretaña- Dr. Mathias he and Dr. Salazar and the portuguese Government thought about the Spanish situation he replied with what was, even for him, unusual vigour. The prime interest of all concerned (except communists) was, he declared, the avoidance of another civil war in Spain; and, consequently, the avoidance of any steps which risqued provoquing it" ${ }^{32}$.
}

E! auténtico peligro, según el ministro portugués, de la intervención en España estaba en la posible provocación de un caos comunista que sería automáticamente perjudicial para los intereses británicos en la Península, echando al país, literalmente, en los brazos de una potencia que no se caracterizaba, precisamente, por su apego a los principios democráticos occidentales. zando.

El "sitio", pues, de España en Europa y en el mundo estaba comen-

Una nota interna del Foreign Office, fechada el 9 de marzo, podría servirnos de ilustración al efecto que en la participación española en Conferencias técnicas internacionales, estaba teniendo la condena formal del Régimen: En esencia, los comités organizadores de estas conferencias internacionales europeas sobre temas específicos (navegación; meteorología, etc.), se pronunciaban en contra de la invitación a España ante cualquier indicio de protesta por parte de otros asistentes - léase URSS o

${ }^{32}$ Despacho n. ${ }^{\circ} 67 \mathrm{M} \mathrm{55/189/46}$ del embajador británico en Lisboa a su ministro de Asuntos Exteriores, 7 de marzo de 1946. PRO FO 371/60446. 
países escandinavos- quienes jugaban casi siempre con la baza de su no comparecencia.

El Foreign Office buscaba ya a esas alturas un principio fijo que permitiera conocer de antemano cuáles habían de ser las condiciones que determinarian la presencia o no de España en dichas Conferencias, habiéndose dado el caso en alguna de ellas de que las delegaciones española y soviética habían comido juntas en la misma mesa sin ningún problema.

El proverbial pragmatismo británico impulsó una propuesta en el sentido de procurar la invitación de España a las Conferencias de carácter técnico, y negar su asistencia a las de índole política, porque...

\begin{abstract}
"Spain is a country of Western Europe, with which, in spite of our bad political relations at the present moment, we have constant commercial intercourse, we have a british air service flying to Madrid, british ships calling at spanish ports and so forth. It is clearly necessary therefore that Spain should, so far as political considerations permit, be brought into any international arrangements designed to facilitate commercial intercourse, etc." ${ }^{33}$.
\end{abstract}

Por ende, el Foreign Office consideraba necesario fomentar una fuerte y coherente oposición interna al régimen español, soslayando el peligro de la guerra civil. Y aunque acusaba a Portugal, por ejemplo, de desconocer a sabiendas la realidad de la opinión pública internacional respecto al "caso español", había instado el 25 de marzo de 1946 a su embajador en Lisboa, Mr. O'Malley, que se enterara de qué clase de consejos estaba dando o podía dar Salazar al general Franco, para que mejorara su situación interna, de acuerdo a las ideas que flotaban en la mente de los países occidentales ${ }^{34}$.

Precisamente éstos y otros paises, espoleados por la delegación pola$\mathrm{ca}$, iniciaron en el mes de abril una dura dinámica de condena al régimen del general Franco en el seno de la ONU.

El día diecisiete de dicho mes, el delegado polaco (Mr. Lange), presentó una requisitoria ante el Consejo de Seguridad de la Organización de las Naciones Unidas en la que se declaraba a España como una amenaza para la paz y la seguridad internacionales, arguyendo la existencia en su

33 "Attendance of Spain at international Conferences". Nota interior del Foreign Office, fechada en Londres el 9 de marzo de 1946. PRO FO 371/60453.

${ }^{34}$ Despacho del Foreign Office al embajador británico en Lisboa, 25 de marzo de 1946. PRO FO $371 / 60446$. 
territorio nacional de varios miles de refugiados alemanes dotados de armamento perfeccionado, y de investigaciones sobre armas atómicas a cargo de científicos, también de nacionalidad alemana, en unos supuestos laboratorios ubicados en el pueblo de Ocaña. Proponía la delegación polaca que en base a ello se rompieran las relaciones diplomáticas con España, y que un subcomité de cinco países fuese creado para estudiar la propuesta (como se hizo). Al mismo tiempo, los refugiados republicanos repartieron profusamente en la Asamblea un extensísimo Memorándum en donde confirmaban todo lo dicho por Polonia.

La reacción del Régimen no se hizo esperar, habida cuenta de la proporción que tomaba el ya bautizado "caso español", y apelando a unas declaraciones efectuadas por el secretario de Estado norteamericano, Summer Welles, se hizo hincapié en el peligro derivado de la expansión soviética en el Mar Mediterráneo que se vería potenciado si, de resultas de una nueva guerra civil, caía España en manos comunistas. El Ministerio español de Asuntos Exteriores habló de que el subcomité de la ONU estaba violando el principio de la no-intervención en los asuntos internos de España y reivindicaba el hecho — probado, según se argumentaba- de que España no habia violado en ningún momento el justo orden internacional ${ }^{35}$.

Hasta la vuelta del verano, y tras la resolución del Proceso de Nuremberg (el $10^{\circ}$ de octubre) no volvería a tratarse la cuestión relativa a España en la ONU. El dos de diciembre, un delegado americano en la Asamblea, tildó de "fascista" al régimen del general Franco y propuso su exclusión de las agencias dependientes de la Organización, al mismo tiempo que sus miembros rompian relaciones con él. El día 9, una manifestación a la par espontánea y organizada aglutinó oficialmente en la Plaza de Oriente de Madrid al pueblo español alrededor del general Franco.

El 13 de diciembre, y por 34 votos a favor, trece abstenciones y seis votos en contra, la Asamblea General de las Naciones Unidas aprobó la recomendación hecha a los países miembros en orden a la retirada de Madrid de sus embajadores y ministros plenipotenciarios.

Sin embargo, el flujo comercial siguió incrementándose y envíos importantes del cono sur ayudarían a paliar las graves dificultades económicas por las que estaba pasando el país. España fue a la ONU lo que años antes habían sido Italia, Alemania y Japón a la Sociedad de Naciones.

${ }^{35}$ Boletín extraordinario de la Embajada de España en Río de Janeiro titulado: «El punto de vista de nuestro gobierno ante el llamado "caso español" en la ONU». de fecha 28 de junio de 1946. APG Legajo n. ${ }^{\circ} 12$ Jefatura del Estado. 
Como decía Descola, el análisis del escrutinio:

\begin{abstract}
“... appelle deux remarques. Les treize abstentions comprendront la plupari des pays arabes. Les six votes contraires seront ceux decertaines Republiques sudaméricaines. Le texto est sévère, mais son dernier paragraphe deviendra una clause de style, car l'attitude des Etats, loin de se durcir, ne fere que s'assouplir au cours des interventions ultérieures sur l'Espagne. La décision de L'ONU, comme la démarche de Bidault, est un acte de morale internationales. Cette fois L'ONU, conträirement aux déclarations précédentes, intervient franchement dans les affaires intérieures espagnoles. Elle invite le peple à procéder à des eléctions libres pour se donner un régime démocratique. A la fin de l'année, il ne reste plus à Madrid que deux ambassadeurs - celui du Vatican at celui du Portugal-et deux ministres plénipotentiaires - ceux de Suisse et d'Irlande. L'Espagne est mise au ban du monde démocratique" ${ }^{36}$.
\end{abstract}

Un artículo publicado profusamente en la prensa española durante los primeros días del mes de enero de 1947 explicaba en düros términos el porqué fundamental de esta mise au ban, y razonaba cartesianamente que ello era debido a la masonería internacional, lacra que atizaba todas las hydras anti-españolas y se oponía a su catolicidad y fair-play exterior.

"Hakin Boor", articulista del periódico Arriba publicaba el 5 de marzo una extensa diatriba contra la condena de la ONU, criticando el concepto de Democracia tan extensamente manido, y echando en cara la desvergüenza masónica mundial, que pretendía vengarse en cierta medida del éxito obtenido por las autoridades españolas en su extirpación: El diario La Tarde de Málaga calcaba íntegramente dicho artículo dos días después.

Ese mismo mes sería testigo de la apertura del "puente-argentino" que serviría para paliar el grave déficit de abastecimientos diplomáticos y económicos que sufría el Régimen; mientras éste ultimaba el proyecto de "re-democratización" interior que había de culminar con el referéndum sobre la Ley de Sucesión y el establecimiento de facto en España de una Monarquía sin rey.

\title{
ESPAÑA, AL MARGEN DE LA AYUDA MARSHALL
}

Como consecuencia del fracaso de la Conferencia de Moscú donde el Gobierno soviético rechazó la propuesta norteamericana de un tratado

${ }^{36}$ Jean Descola, O Espagne, Albin Michel, París, 1976. pág. 321. 
de 25 años de duración entre las cuatro grandes potencias, creció en los Estados Unidos una corriente en pro de la federación de los países europeos, sin duda fomentada por el expansionismo de los países de la Iron Courtain.

Lord Inverchapel, embajador británico en Washington, escribía al Foreign Office el 16 de mayo de 1947 el interés que Norteamérica tenía en el planteamiento de una unión europea que incluyera a todas las naciones occidentales cualificadas especialmente por su respeto a las libertades políticas, económicas, sociales y religiosas de sus ciudadanos. Propuesta que incluía una nueva versión del problema alemán y que estaba en relación directa con la doctrina Marshall.

Inverchapel no hacia referencia a España pero, como es lógico, la definición de las características que se presumía habian de cumplir los países llamados a participar en el proyecto, la excluían intrínsecamente. Los tres pilares básicos de la unión europea deberían ser Inglaterra, Francia y Alemania, cuyos sentimientos anti-soviéticos, junto a sus esperanzas de renovación económica empezaban a ser petentes ${ }^{37}$.

Para establecer un puente entre los Estados Unidos y los paises europeos en trance de reconstrucción, el general Marshall esbozó un plan de ayuda a Europa que expuso por primera vez en un celebrado discurso pronunciado en Harvard el 5 de junio de 1947.

España por su propio carácter interno, estaba llamada a no beneficiarse de dicho proyecto al continuar en alza el boicot al Régimen recomendado por las Naciones Unidas.

De hecho, unos meses después, el delegado británico en la Conferencia para la reconstrucción europea celebrada en París, telegrafiaba al Foreign Office el $1 .^{\circ}$ de agosto la opinión de Jean Monnet, uno de los padres de la nueva Europa, sobre las medidas necesarias para revitalizar la economía europea:

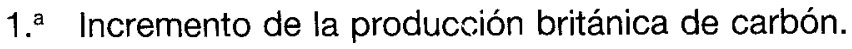

2. Incremento de la producción agrícola en Italia y Francia.

${ }^{37}$ Despacho $n{ }^{\circ} 1.136$ del embajador británico en Washington al Foreign Office, 16 de mayo de 1947 . PRO FO $371 / 61047$. 


\section{Consolidación de la seguridad financiera en Francia e Italia ${ }^{38}$.}

Esas medidas, fomentadas por la voluntad común -que ya había arengado Churchill con su "levántate Europa» en Suiza, años atrás- y los dólares USA, serían vistas pasar de largo en la Península, retardando en muchos años el despegue económico español y dificultando de forma casi insalvable su política europea.

Como respondió posteriormente Martín Artajo a Jean Descola ante su pregunta de cuál había sido el humor del general Franco durante el período en que España era rechazada por las grandes potencias:

«Excelente. Su calma era inquebrantable. Un día en que le informaba de la falta de combustible como consecuencia del bloqueo aliado me respondió encogiéndose de hombros: bien, volveremos a las mulas" ${ }^{39}$.

La repercusión económica de la carencia de «enganche» al plan de reconstrucción europeo que se estaba gestando y que después se llevaría a la práctica, nos la puede explicar brevemente el profesor Senén Florensa:

«Los amagos de cambio de orientación ideológica del régimen no consiguen evitar el establecimiento del cerco internacional. La Europa que se apresta a su reconstrucción a través del plan Marshall en 1948 no concede un lugar a España en sus esquemas de cooperación... Además de la inexistencia de la ayuda, la dificultad de los intercambios con el exterior arrecia sin que puedan importarse todavía los ya tan necesarios equipos y materias primas. La voluntad de mantenimiento del tipo de cambio inalterable de 11 ptas. igual a un dólar no encuentra otra salida, para mantener la ficción, que la extensión del peculiar sistema de las cuentas especiales, por lo que los exportadores españoles intentan malvender en el exterior en la seguridad de realizar un pingüe beneficio con las importaciones por las divisas que se les reservan, que alcanzarán precios extraordinarios en el interior... Continúa la intervención y el control total de la economia, la desaparición de un tercio de las cosechas por el portillo del estrperlo hacia los mercados negros, las cartillas de racionamiento para lo que queda de la producción más lo importado, la proliferación de todo tipo de productos industriales sucedáneos, más que sustitutos, de la importación en condiciones de costos imperiales y la voluntad industrializadora del Estado en persecución de la autarquía» ${ }^{40}$.

${ }^{38}$ Telegrama cifrado n. 75 del delegado británico en la Conferencia de reconstrucción europea celebrada en París, 1 de agosto de 1947. PRO FO 371/62415.

39 Jean DESCOLA, op. cit. pág. 323.

${ }^{40}$ Senén Florensa, «La España del Plan de Estabilización» en Historia Contemporánea del siglo XX. Volúmen 26, Historia 16, pág. 88. 
El Régimen, como se ve, afrontaba en condiciones muy adversas su futuro a corto y medio plazo. Por el contrario, los principales países europeos iniciaban una cuenta atrás simbólica que habría de proyectarles hacia adelante con formidable impulso.

En lo que se refiere a la oposición organizada al franquismo, también estas vicisitudes de 1947 les iban a hacer una importante mella: a consecuencia de la celebración del referéndum sobre la Ley de Sucesión, el Gobierno republicano en el exilio - de marcadisima tendencia izquierdista- cayó durante la primavera y supuso, además, la negociación del Partido Socialista con los monárquicos afines a Don Juan de Borbón, considerada entonces la más importante de cuantas fuerzas de oposición al régimen de Franco se hallaban fuera de España. Hacia ellos, precisamente, había sido lanzado el ya citado referéndum, suavizando el aspecto exterior de la Dictadura y dando nuevos ánimos a quienes en España (y aún fuera de ella) seguían o pudieran seguir pensando en el advenimiento de una Monarquía à la façon de Franco.

Cuenta Salvador de Madariaga en su monumental España que...

\begin{abstract}
«...en septiembre de 1947 el Partido Socialista Español publicó una declaración favorable a un acuerdo de tal índole (con los monárquicos)...» y que «...en octubre de 1947 don Indalecio Prieto y don José María Gil Robles se entrevistaron en Londres y fueron recibidos por Ernest Bevin, el ministro (socialista) de Estado, uno de los pocos adversarios sinceros del régimen. La gestión logró pleno éxito. Se redactó una declaración que respondía a los requisitos de la nota de las tres potencias y a la resolución de las Naciones Unidas de 12 de diciembre de 1946; y se remitió esta declaración conjunta (separada y paralelamente por socialistas y monárquicos) a los Gobiernos de Bélgica, Estados Unidos, Francia, Gran Bretaña, Holanda y Luxemburgo. El acuerdo estipulaba un gobierno provisional, un plebiscito para decidir la forma de gobierno y la inmediata incorporación de España al Pacto de Bruselas» ${ }^{41}$.
\end{abstract}

También habla Madariaga de que el fracaso del esfuerzo componedor vino por el lado monárquico y por la aproximación que parlamentarios americanos y el propio Churchill hacían y habían hecho hacia el general Franco y su sistema de gobierno.

Un Boletín secreto de la Dirección General de Seguridad ${ }^{42}$ confirmaba al subsecretario español de Asuntos Exteriores el bajo estado moral en

${ }^{41}$ Salvador de MadariAga, España. Ensayo de Historia Contemporánea, Ed. Espasa Calpe, Madrid 1979, pág. 515.

${ }^{42}$ Boletín decenal secreto n. ${ }^{\circ} 26 \mathrm{VI}$ del Servicio de Información de la Dirección General de Seguridad. Ref. Expd. 8026 sobre "Actividades de expatriados y rojos". Madrid, 3 de octubre de 1947. AMAE Legajo R-3148, expediente 9. 
que se encontraban los diversos grupos de exiliados republicanos, quienes parecian haberse convencido, por fin, de que la ONU jamás les apoyaria convenientemente.

De todas formas, ya se empezaban a ver los primeros indicios del cambio de rumbo en la política occidental con respecto a España, paralelamente a los primeros compases de la llamada guerra fría.

El 9 de octubre de 1947 fue creado el Kominform, especie de internacional comunista, que produjo espanto en los medios norteamericanos y aliados occidentales al comprender en qué quedaban las promesas de Stalin respecto a la exportación de la Revolución en el mundo.

La Asamblea de las Naciones Unidas, en su sesión del 17 de noviembre, no ratificó el cuerpo principal de la Resolución de 1946, donde se recomendaba la retirada de los jefes de misión en España; y se reservaba la capacidad de imponer sanciones contra el régimen español ${ }^{43}$.

Pero esto no quería decir que el mundo occidental estuviera abriendo el muro que rodeaba al «país-maldito», sino que los intereses geoestratégicos de las dos Potencias estaban recolocando a España en la esfera de influencia y en la zona de Europa que siempre le había correspondido.

Julio Alvarez del Vayo publicaba el 22 de noviembre de 1947 un artículo en el periódico británico The Nation, donde comentaba el tratamiento hecho del "caso español» en las Naciones Unidas y criticaba en él la actitud norteamericana, ya en franco distanciamiento de cualquier planteamiento de Bon voisin de los países comunistas, en un tema que, como el español, les había unido un año antes:

«La actitud y táctica de la delegación norteamericana prueba una vez más que una política exterior basada en el único objetivo de detener a Rusia, tiene que terminar en la dejación de todo principo democrático. No es mucho que semejante política resulte difícil de explicar en un lenguaje lógico o convincente" ${ }^{44}$.

Por obra y gracia, pues, de los Estados Unidos y en virtud de su distanciamiento de la URSS, toda la política española de los paises occidentales

43 Ramón Tamames, op. cit. pág. 519.

44 Artículo de Julio ALVAREZ DEL VAYO en el diario The Nation, 22 de noviembre de 1947. AMAE. Legajo R-3148, expediente 9. 
iba a encontrar su primer punto de rotación favorable a la permanencia del régimen franquista como tal justamente a finales del año 1947.

La escasa operancia de los líderes exiliados, la hábil política interior de represión y de blanqueamiento exterior que desarrolló el general Franco, le habían conducido lenta, pero casi inexorablemente a contemplar con mayor optimismo, la continuidad del régimen político que había querido para España y la consecución de su permanencia en el poder supremo de la nación. 